\title{
Menghitung Kapasitas Kapasitor Sebagai Koreksi Faktor Daya Pada Pelanggan Rumah Tangga 6600 VA
}

\author{
Safira Nabilla Julianti ${ }^{1}$; Ibnu Hajar ${ }^{2}$ \\ 1,2Teknik Elektro, Institut Teknologi PLN, Jakarta \\ ${ }^{1}$ safnabilla@gmail.com
}

\begin{abstract}
It is undeniable that the low value of the power factor can cause problems with the electrical load in the form of power consumed that does not match the installed power. $A$ low power factor can cause power usage to be less than optimal and current increase so that it can result in increased heat losses in the cable. From the data, there are still many customers who have a power factor of 0.5 to 0.7 meaning they are below the standard, for this reason it is necessary to improve the power factor value by installing capacitors where it is necessary to calculate the capacitor's capacity according to the installed power, so as to optimize the distribution of funds and reduce heat losses from the conductor so that the distribution condition is more stable. The diagram method is used, a diagram showing the $k V A R$ value is needed before and after compensation. With the improvement of the power factor in accordance with the standard, a more optimal use of electric power is obtained. From the results of the calculations, the average capacity of the capacitor used for household customers with a power of 6600 VA is $3,74 \times 10^{-5}$ Farad or $37.4 \mathrm{~F}$.
\end{abstract}

Keywords: power factor, capacitor, power factor improvement

\begin{abstract}
ABSTRAK
Tidak dapat dipungkiri rendahnya nilai faktor daya dapat menimbulkan masalah pada beban listrik berupa daya yang dikonsumsi tidak sesuai dengan daya yang terpasang. Faktor daya yang rendah dapat menyebabkan penggunaan daya menjadi kurang optimal dan kebutuhan arus meningkat sehingga dapat mengakibatkan rugi rugi panas pada kabel menjadi meningkat. Dari data masih didapatkan banyak pelanggan yang memiliki faktor daya 0,5 sampai 0,7 yang berarti berada dibawah standar, untuk itu diperlukan perbaikan nilai faktor daya pada instalasi dengan melakukan pemasangan kapasitor dimana untuk itu diperlukan perhitungan kapasitas kapasitor sesuai dengan daya yang terpasang, sehingga dapat mengoptimalkan penyaluran dana dan mengurangi rugi rugi panas dari kabel penghantar sehingga keadaan jaringan lebih stabil. Metode yang digunakan yaitu dengan metode diagram, dimana untuk mengetahui nilai kapasitor diperlukan diagram yang menunjukkan nilai kVAR sebelum dan sesudah kompensasi. Dengan perbaikan faktor daya yang sesuai dengan standar maka didapatkan pemakaian daya listrik yang lebih optimal. Dimana dari hasil perhitungan yang dilakukan didapatkan rata rata kapasitas kapasitor yang digunakan untuk pelanggan rumah tangga dengan daya 6600 VA yaitu sebesar $3,74 \times 10^{-5} \mathrm{Farad}$ atau $37,4 \mu \mathrm{F}$.
\end{abstract}

Kata kunci: faktor daya, kapasitor, perbaikan faktor daya 


\section{PENDAHULUAN}

Pemakaian energi listrik oleh variasi beban dapat menyebabkan masalah, salah satunya yaitu rendahnya faktor daya listrik dan terjadinya drop voltage. Pada wilayah penelitian masih banyak ditemukan pelanggan rumah tangga dengan daya 6600 VA yang memiliki faktor daya yang berada dibawah standar. Dimana rata rata faktor daya yang dimiliki pelanggan yaitu 0,5 sampai 0,7 , hal ini menyebabkan penyaluran dari pada jaringan area tinjauan menjadi kurang optimal. Oleh karena hal ini, diperlukan perbaikan faktor daya dengan melakukan pemasangan kapasitor yang dimaksudkan agar penyaluran daya ke pelanggan menjadi lebih optimal. Kapasitor bank mengadopsi metode peningkatan faktor daya ( $\cos \varphi$ ), yang dapat mengurangi daya reaktif (VAR). Apabila besarnya daya reaktif yang disuplai dari sisi utilitas tersebut berkurang, maka faktor daya akan membaik dan nilainya akan mendekati 1 sesuai dengan standar untuk faktor daya menurut PLN yaitu $>85 \%$ [14]. Sedangkan, batas toleransi untuk tegangan standar pada sisi pelayanan yaitu sebesar $+5 \%$ dan $-10 \%$ [16].

\section{METODE/PERANCANGAN PENELITIAN}

\subsection{Teknik Pengambilan Data}

Pengumpulan data dilakukan pada tanggal 1 Maret 2021 sampai 31 Maret $2021 \mathrm{di}$ PT. PLN (persero) UP3 Cikokol, dengan data berupa data tegangan, arus, daya semu, daya aktif, daya reaktif dan faktor daya di bulan maret pada beberapa pelanggan rumah tangga yang dijadikan sampel penelitian. Pengambilan data dilakukan dengan cara mengambil data yang dibutuhkan pada bagian Jaringan di UP3 Cikokol. Secara sederhana proses penelitian dapat dijelaskan melalui diagram alir pada Gambar 1.

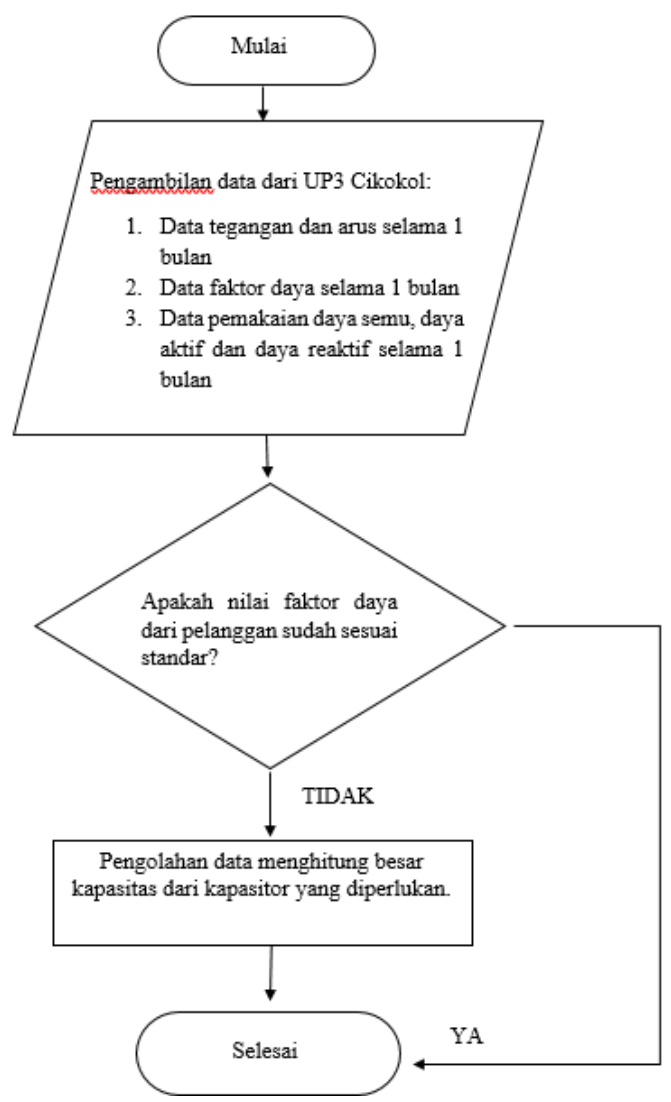

Gambar 1. Diagram Alir Penelitian 
Setelah data untuk keperluan penelitian didapatkan, langkah selanjutnya yaitu menganalisis data. Metode analisis data berfungsi untuk menyimpulkan hasil dari penelitian yang dilakukan. Tahapan-tahapan yang dilakukan antara lain yaitu:

1. Menentukan pelanggan rumah tangga dengan kontrak VA yang sama untuk dijadikan sampel penelitian.

2. Menghitung kebutuhan kapasitor untuk perbaikan faktor daya Menghitung kompensasi daya reaktif

3. Menghitung nilai kapasitas dari kapasitor

4. Menghitung persentase penghematan

\subsection{Menghitung Kebutuhan Kapasitor}

Metode dapat digunakan untuk menghitung nilai kapasitas kapasitor yaitu dengan metode diagram. Untuk mengetahui nilai kapasitor, diperlukan diagram yang menunjukkan nilai kVAR sebelum dan sesudah kompensasi yang dapat digambarkan sebagai berikut [5]:

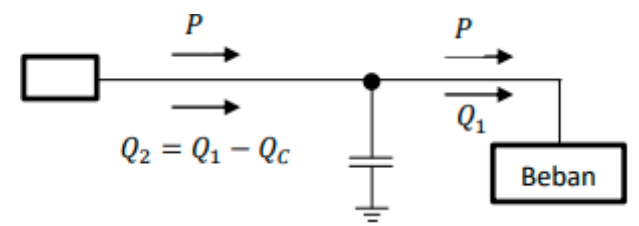

(a)

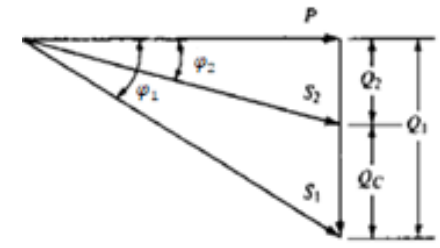

(b)

Gambar 2. Ilustrasi perbaikan faktor daya

Dari gambar 2 di atas, dapat dilihat bahwa kapasitor merupakan sumber dari daya reaktif - kapasitif yang nantinya akan menekan daya reaktif dari beban. Dengan anggapan bahwa beban disuplai oleh daya aktif $(P)$, daya reaktif $\left(Q_{1}\right)$, dan daya semu $\left(\mathrm{S}_{1}\right)$, maka dapat dirumuskan yaitu:

$$
\operatorname{Cos} \theta_{1}=\frac{P}{\sqrt{P^{2}+\mathrm{Q}^{2}}}
$$

Bila kapasitor dipasang parallel pada sisi beban dengan kapasitas QC kVAR, maka faktor dayanya diperbaiki menjadi:

$$
\operatorname{Cos} \theta_{2}=\frac{P}{S_{2}}=\frac{P}{\sqrt{P^{2}+Q^{2}}}
$$

Atau

$\operatorname{Cos} \theta_{2}=\frac{P}{\sqrt{P^{2}+(\mathrm{Q} 1-\mathrm{QC})^{2}}}$

$\mathrm{S}=\frac{P}{\cos \theta_{2}}$

$$
Q=\sqrt{S_{2}{ }^{2}-P^{2}}
$$

Untuk menghitung besarnya daya aktif yang terpakai dapat digunakan rumus [3]:

$$
P=S \times \cos \theta_{2}
$$


Apabila power factor awal dilambangkan $\operatorname{Cos} \varphi_{1}$ lalu power factor yang diperbaiki dilambangkan $\operatorname{Cos} \varphi_{2}$ maka besarnya kapasitor $\left(Q_{c}\right)$ dapat rumuskan sebagai berikut [3]:

$Q_{C}=P\left(\tan \varphi_{1}-\tan \varphi_{2}\right) \mathrm{kVAR}$

Keterangan:

$\mathrm{S}_{1}=$ Daya semu awal (sebelum dikompensasi) (VA)

$\mathrm{P}=$ Daya aktif beban (Watt)

$\operatorname{Cos} \varphi_{1}=$ Faktor daya awal (sebelum dikompensasi) (Rad/Deg)

$\mathrm{Q}_{1}=$ Daya reaktif (sebelum dikompensasi) (VAR)

$\mathrm{S}_{2}=$ Daya semu yang diinginkan (setelah dikompensasi) (VA)

$\operatorname{Cos} \varphi_{2}=$ Faktor daya yang diharapkan (Rad/Deg)

$\mathrm{Q}_{2}=$ Daya reaktif yang setelah dikompensasi (VAR)

$\mathrm{Q}_{\mathrm{C}}=$ Rating kapasitor (kVAR)

Perbaikan faktor daya juga berdampak pada berkurangnya nillai arus yang juga dapat mengurangi rugi rugi dari panas pada kabel yang dialiri arus, dimana semakin besar arus yang mengalir makan penghantar akan sekalin panas. Perbandingan berbedaan nilai arus sebelum dilakukan pemasangan kapasitor dengan setelah dilakukan pemasangan kapasitor dapat dirumuskan sebagai berikut [2]:

$I_{n}=\frac{P}{V \times \cos \theta_{n}}$

Dimana:

$\mathrm{P}=$ daya aktif (Watt)

$I_{n}=$ arus dengan faktor daya awal/baru (Ampere)

$\mathrm{V}=$ tegangan (Volt)

$\cos \theta_{n}=$ faktor daya awal/baru

\subsection{Menghitung Kapasitas Kapasitor}

Untuk memperbaiki nilai faktor daya, maka diperlukan perhitungan dari nilai kapasitas kapasitor yang sesuai. Untuk menghitung besarnya nilai kapasitas dari capasitor bisa menggunakan persamaan [5]:

$$
C=\frac{Q_{C}}{V^{2} X \omega}
$$

$$
\begin{aligned}
& \text { Dimana : } \\
& \text { C = Nilai capasitor (Farad) } \\
& \text { Qc = VAR capasitor } \\
& \text { V = Tegangan (Volt) } \\
& \begin{array}{ll}
\omega=2 \pi f
\end{array}
\end{aligned}
$$

Setelah mengetahui nilai dari kapasitas kapasitor yang dapat digunakan dan selisih arus sebelum pemasangan kapasitor dengan arus setelah pemasangan kapasitor, maka selanjutnya dapat dicari nilai persentase penghematan yang dicapai setelah melakukan pemasangan kapasitor dnegan rumus [9]:

$\%$ Penghematan $=I_{1}-I_{2}$

Dimana: 
$I_{1}=$ arus dengan faktor daya awal

$I_{2}=$ arus dengan faktor daya yang diinginkan

\section{HASIL DAN PEMBAHASAN}

\subsection{Data Pelanggan Rumah Tangga}

Tabel 1 dan table 2 merupakan data 30 pelanggan rumah tangga dengan daya 6600 VA yang diambil dalam waktu 1 bulan yaitu dari tanggal 1 maret 2021 sampai dengan 31 maret 2021.

Tabel 1. Data Rumah 1-15

\begin{tabular}{|c|c|c|c|c|c|c|}
\hline Data Rumah & $\begin{array}{c}\text { Solts } \\
\text { (Folt }\end{array}$ & $\begin{array}{c}I_{=x: 2-r a x} \\
\text { (Ampere) }\end{array}$ & $\begin{array}{c}P F_{\text {rats- }} \\
\text { ratt }\end{array}$ & $\begin{array}{l}P_{\text {rats:a: }} \\
\text { (Wiatt) }\end{array}$ & $\begin{array}{c}\text { Qrat } \\
\text { (rat } \\
\text { (at) }\end{array}$ & $\begin{array}{c}S_{\text {enteratu }} \\
\text { (bit) }\end{array}$ \\
\hline RLALAH 1 & $218 . \$ 6$ & 3.211 & $0.5+3$ & $11 \div 6,424$ & 1020,25 & 1491,187 \\
\hline RLALAH ? & 226.438 & 0.915 & $0.66 \mathbf{s}$ & 295.006 & 270.5 & 530.246 \\
\hline RLALAH 3 & 219.998 & 3.765 & 0.744 & $165(0,306$ & 1577,97 & $17 ? 1,536$ \\
\hline RLALAH A & 223.717 & 0.1 & -0.501 & 91.163 & 66.992 & 137.36 \\
\hline RLALAH s & 223.167 & 1.193 & -0.806 & 671.674 & 279.919 & 723.192 \\
\hline RLALAH 6 & 227.0194 & 0.978 & 0.736 & 489.719 & $26+.6018$ & $6 \pm 2.399$ \\
\hline RLALAH 7 & 218.906 & 1.184 & 63 & 562.958 & 378.464 & 680.939 \\
\hline RLALAH 8 & 221.309 & 2.534 & $0.5+3$ & $8479 \div 1$ & 833,885 & 900.903 \\
\hline RLALAH 9 & 233.372 & 1.918 & $0.6 \geq 8$ & 634.254 & $606.3+5$ & 835.785 \\
\hline RLALAH 10 & 227.0194 & 1.42 & 0.528 & 504.634 & 17+.5:8 & 614.539 \\
\hline RLALAH 11 & 214.324 & 1.614 & 0.537 & $\$ 51.286$ & 505.217 & 633.678 \\
\hline RLALAH l? & 229.017 & 2.174 & 0.746 & 746.634 & $57+.4 \div 1$ & 973.311 \\
\hline RLALAH 13 & 230.202 & 3.252 & $0.7 ? 6$ & $11 ? 3,996$ & 81:.797 & 1557,79 \\
\hline RLALAH 14 & 213,3 & 2.12 & $0.5+2$ & 765.566 & 695.111 & 958.359 \\
\hline RLALAH 15 & 210.039 & 1.339 & 0.761 & 360.871 & 315.341 & 405.270 \\
\hline
\end{tabular}

Tabel 2. Data Rumah 16-30

\begin{tabular}{|c|c|c|c|c|c|c|}
\hline Data Rumah & $\begin{array}{l}\text { Finerrat } \\
\text { (Tolt) }\end{array}$ & $\begin{array}{c}I_{\text {-azi-not }} \\
\text { (Ampere) }\end{array}$ & 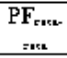 & $\begin{array}{c}P_{\text {rats:an: }} \\
\text { (Wiatt) }\end{array}$ & $\begin{array}{l}Q_{\text {rats:an: }} \\
(\mathrm{G}: \mathrm{R})\end{array}$ & $\begin{array}{c}S_{\text {Euseratu }} \\
\left(\mathrm{f}^{\prime} \mathrm{A}\right)\end{array}$ \\
\hline RLALAH 16 & 217.917 & 1.191 & 0.597 & 465.465 & 360.728 & 671.366 \\
\hline RLPLAH 17 & 299.017 & 2.174 & 0,689 & 726.15 & $57+.4 \div 1$ & $971.30 \bar{i}$ \\
\hline RLMLAH 18 & 228.896 & $1.4 \$ \$$ & 0,69 & 590,01 & 426.991 & 703.748 \\
\hline RLILAH 19 & 225.14 & 2.337 & 0,609 & 954.436 & $7 \pm 28: 6$ & $11: 1.919$ \\
\hline RLILAH 20 & 228.335 & 1.213 & 0,69 & $\$ 23.653$ & 350.496 & 739.467 \\
\hline RLALAH 21 & 228.724 & 0.983 & 0,63 & 387.297 & $296 .(11) \overline{7}$ & 455.394 \\
\hline RLALAH 22 & 213.151 & 5.471 & 0,732 & 2741,395 & 1376,011 & 3405,1 \\
\hline RLILAH 23 & 215.768 & 2.916 & 0,754 & 1616,725 & 748.933 & 1906.531 \\
\hline RLPLAH 24 & 230.883 & 2.645 & 0,78 & 1311,381 & 662.001 & $1+61,603$ \\
\hline RLALAH 25 & 215.399 & 2.55S & 0,746 & 713.436 & 665.1 & 830.849 \\
\hline RLALAH 26 & 220.829 & 3.843 & $0,7.49$ & 1686,485 & 973.992 & 1894,531 \\
\hline RLPLAH 27 & 234.993 & 2.77 & 0,683 & 1000,196 & $8 \geq 3,645$ & $1+13.499$ \\
\hline RLALAH 28 & 239.64 & 2.241 & 0,629 & $994.08:$ & 692.987 & 1180,782 \\
\hline RLALAH 29 & 215.893 & 2.032 & 0,711 & 930.294 & 588.913 & $10+4.666$ \\
\hline RLALAH 30 & 213.076 & 2.311 & 0,524 & $8+1.526$ & 760.413 & $1 \geq 73,414$ \\
\hline
\end{tabular}




\subsection{Perhitungan Kapasitas Kapasitor}

Berikut merupakan perhitungan kapasitas kapasitor untuk salah satu rumah:

a) Perhitungan Kebutuhan Kapasitor

$$
\begin{aligned}
& S_{2}=\frac{P}{\cos \varphi_{2}} \\
& S_{2}=\frac{1173,296 \mathrm{~W}}{0,95} \\
& =1235,048 \mathrm{VA}
\end{aligned}
$$

$$
\begin{gathered}
Q_{2}=\sqrt{S_{2}{ }^{2}-P^{2}} \\
Q_{2}=\sqrt{(1235,048)^{2}-(1173,296)^{2}} \\
=385,642 \mathrm{VAR} \\
P_{2}=S \times \cos \varphi_{2} \\
=1557,790 \times 0,95 \\
=1479,900 \mathrm{~W}
\end{gathered}
$$

b) Perhitungan arus sebelum dan sesudah perbaikan faktor daya

$$
\begin{aligned}
I_{1} & =\frac{P}{V \times \cos \varphi_{1}} \\
& =\frac{1173,296}{230,202 \times 0,776} \\
& =6,568 \mathrm{~A} \\
I_{2} & =\frac{P}{V \times \cos \varphi_{2}} \\
= & \frac{1173,296}{230,202 \times 0,95} \\
& =5,365 \mathrm{~A}
\end{aligned}
$$

c) Perhitungan kompensasi daya reaktif

$Q_{c}=P\left(\tan \varphi_{1}-\tan \varphi_{2}\right)$

$Q_{c}=1173,296(\tan 43,449-\tan 18,19)$

$$
=608,976 \mathrm{VAR}
$$

d) Menghitung kapasitas kapasitor dan persen penghrmatan

$$
\begin{aligned}
C & =\frac{Q_{c}}{V^{2} \times \omega} \\
& C=\frac{608,976}{(230,202)^{2} \times(2 \times 3,14 \times 50)} \\
= & 3,66 \times 10^{-5} \text { Farad } \\
& \% \text { Penghematan }=I_{1}-I_{2} \\
= & 6,568-5,365 \\
= & 1,203 \mathrm{~A} \\
= & 12,025 \%
\end{aligned}
$$

Dengan cara yang sama, berikut hasil perhitungan dari 30 rumah yang dijadikan data: 
Vol. 11, No. 2, Desember 2021, P-ISSN 2356-1505, E-ISSN 2656-9175

https://doi.org/10.33322/sutet.v11i2.1576

\begin{tabular}{|c|c|c|c|}
\hline & $Q_{c}$ (VAR) & E (Farad) & $\begin{array}{c}\text { \% Penghenatan } \\
\text { (\%) }\end{array}$ \\
\hline 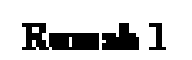 & 1007,800 & $6,7 \times 10^{-2}$ & $27+14$ \\
\hline$R=2$ & 244,479 & $1,52 \times 10^{-5}$ & 17,71 \\
\hline REn $\mathbf{3}$ & 1468,358 & $9,67 \times 10^{-3}$ & 12,12 \\
\hline$R=1$ & $-184,253$ & $1,17 \times 10^{-i}$ & 30.81 \\
\hline$R$ Ras 5 & $-498,487$ & $3,19 \times 10^{-i}$ & 8,11 \\
\hline Rhasl 6 & 160,964 & $1,55 \times 10^{-3}$ & 13,36 \\
\hline$R$ R' 7 & 185,034 & $2,07 \times 10^{-i}$ & 1092 \\
\hline$R=8$ & 285,648 & $4,72 \times 10^{-5}$ & 27,26 \\
\hline RIn= 9 & 793,995 & $3, \overline{3} 1 \times 10^{-3}$ & 20,41 \\
\hline Rmall 10 & 165,862 & $2,78 \times 10^{-i}$ & 28.58 \\
\hline Rmaln 11 & 181,198 & $3,34 \times 10^{-5}$ & 27.77 \\
\hline Rmaln 12 & 245,405 & $2,7 \times 10^{2}$ & 12,02 \\
\hline Rmaln 13 & 385,642 & $3,66 \times 10^{-3}$ & 10,08 \\
\hline Rmal 14 & 251,626 & $4,14 \times 10^{-3}$ & 27.35 \\
\hline Rmald 15 & 118,611 & $1,44 \times 10^{-3}$ & 11,12 \\
\hline
\end{tabular}


Tabel 4. Hasil Perhitungan Rumah 16-30

\begin{tabular}{|c|c|c|c|}
\hline & e. (WAR) & $C$ (Farad) & $\begin{array}{c}\text { \% Penghematast } \\
(\%)\end{array}$ \\
\hline Rumah 16 & $1=990$ & $2,34 \times 10^{-2}$ & 22,89 \\
\hline Rumah 17 & 238.704 & $2,34 \times 10^{-2}$ & 16,01 \\
\hline Rumah 18 & $1939 \geq 5$ & $2,07 \times 10^{-3}$ & 15,83 \\
\hline Rumah 19 & 313.706 & $4,3 \div \times 10^{-2}$ & $\geq I, S I$ \\
\hline Rumah 20 & 172,114 & $1,84 \times 10^{-=}$ & 15,88 \\
\hline Rumah 21 & 992 ד11 & $1,0^{2} \times 10^{-2}$ & 13,ירי \\
\hline Rumah 22 & 90139 & $9,61 \times 10^{-4}$ & 12,95 \\
\hline Rumah 23 & 531,289 & $4,64 \times 10^{-4}$ & 1H,El \\
\hline Rumah 24 & $431,0 \geq 9$ & $3,21 \times 10^{-4}$ & $9,8 \mathrm{~B}$ \\
\hline Rumah 25 & 234.494 & $3,99 \times 10^{-3}$ & 11,01 \\
\hline Rumah 26 & 5ล4319 & $6.5 \times 10^{-5}$ & 11,85 \\
\hline Rumah 27 & 328.745 & $4,47 \times 10^{-4}$ & 16,33 \\
\hline Rumah 28 & $326,73 B$ & $4,14 \times 10^{-3}$ & 14,70 \\
\hline Rumah 29 & 305:70 & $3,12 \times 10^{-3}$ & 14,42 \\
\hline Rumah 30 & 276,59 & $4,65 \times 10^{-2}$ & 28,95 \\
\hline
\end{tabular}

Berdasarkan tabel 3 dan tabei 4 hasil perhitungan kapasitas kapasitor dari seluruh sampel pelanggan rumah tangga, maka didapatkan rata rata kapasitas kapasitor yang diperlukan untuk pelanggan rumah tangga dengan kebutuhan besar yang memiliki daya 6600 VA yaitu sebesar $3,74 \times 10^{-5} \mathrm{Farad}$ atau $37,4 \mu \mathrm{F}$ dengan rata rata persentase penghematan mencapai $17,62 \%$.

\subsection{Penurunan Daya Reaktif}

Selanjutnya, dengan menggunakan aplikasi excel kita dapat melihat grafik dari daya reaktif, faktor daya sebelum dan sesudah pemakaian kapasitor. 


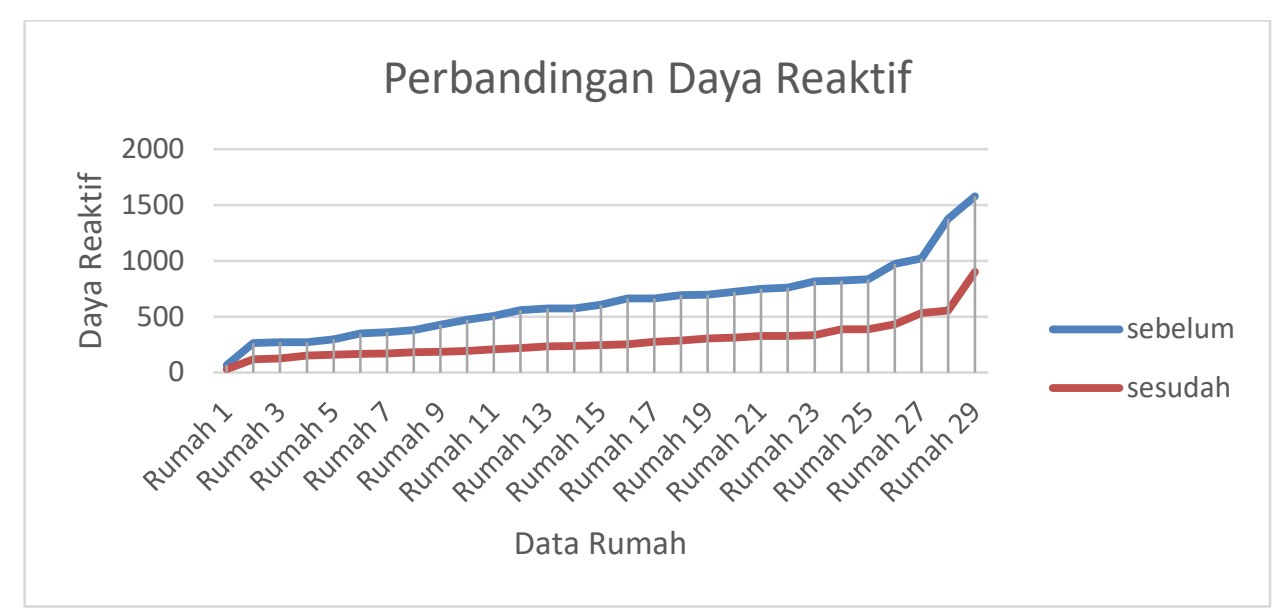

Gambar 3. Grafik Perbandingan Daya Reaktif

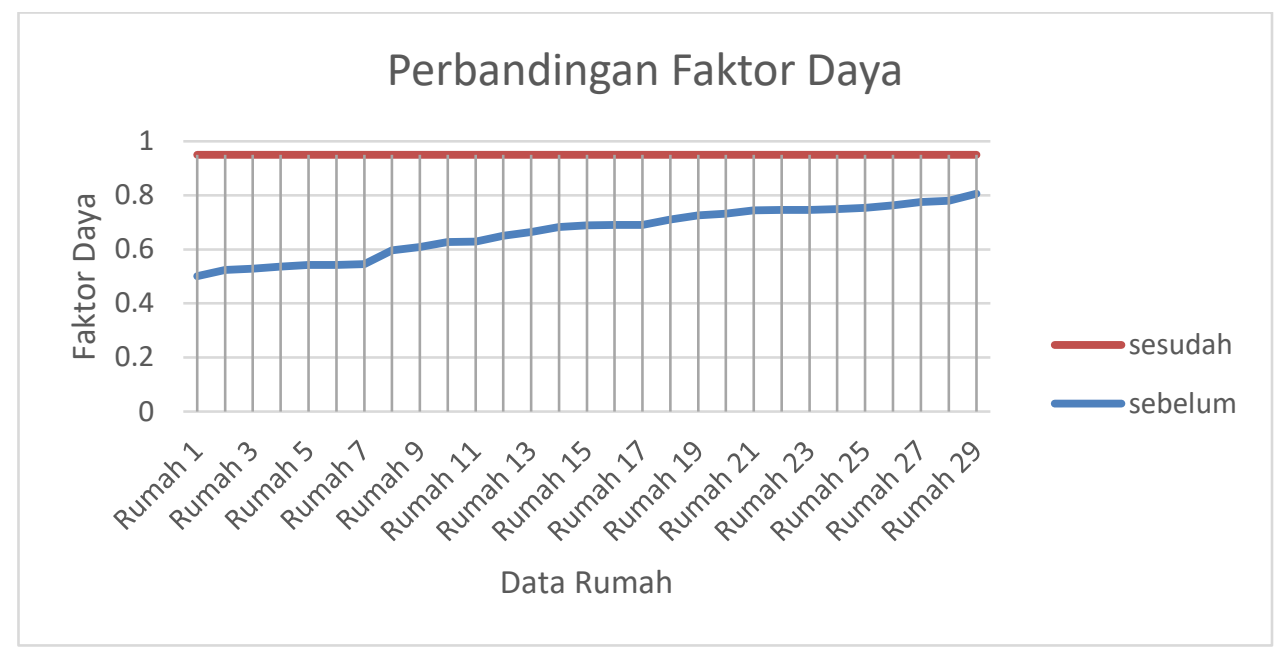

Gambar 4. Grafik Perbandingan Faktor Daya

Dari Gambar 3 dan Gambar 3 di atas dapat grafik memperlihatkan bahwa nilai daya reaktif sesudah dilakukan perbaikan faktor daya mengalami penurunan daripada nilai daya reaktif sebelum dilakukan perbaikan faktor daya.

\section{KESIMPULAN DAN SARAN}

Dari data diperoleh bahwa faktor daya pelanggan rumah tangga yang berada pada UP3 Cikokol berkisar antara 0,5 dan 0,7, hal ini masih sangat jauh dari standar yang diizinkan oleh PLN yaitu 0,85. Karena itu dihitung besar kapasitas kapasitor untuk menaikkan faktor daya tersebut dengan mengasumsikan besar faktor daya yang diinginakan adalah 0,95 dan diperoleh rata-rata besar kapasistas kapasitor yang digunakan untuk pelanggan rumah tangga dengan daya 6600 VA yaitu $3,74 \times 10^{-5}$ Farad atau $37,4 \mu \mathrm{F}$ dengan rata rata persentase penghematan mencapai $17,62 \%$. Dari hasil ini penelitian perlu dilanjutkan pada pelanggan-pelanggan rumah tangga dengan kelompok daya yang lebih kecil (R-1/R-2) dan perlu diperhitungkan untuk memasang kapasitor pada saluran-saluran pelanggan rumah tangga. 


\section{UCAPAN TERIMAKASIH}

Penulis mengucapkan terima kasih kepada Perusahaan Listrik Negara terkhusus pada UP3 Cikokol yang telah memberi dukungan yang membantu pelaksanaan penelitian dengan memberikan data-data yang diperlukan dalam penelitian ini.

\section{DAFTAR PUSTAKA}

[1] Awaluddin. (2018). Perbaikan Faktor Daya Pada Sistem Tenaga Listrik Raw Mill 1 Di Pt. Semen Tonasa Unit Iv Pangkep. Makassar: Universitas Muhammadiyah Makassar.

[2] Bukhari, A., Abidin, Z., \& Stephan. (2012). Perbaikan Power Faktor Pada Konsumen Rumah Tangga Menggunakan Kapasitor Bank. Jurnal IImiah Mahasiswa.

[3] Dani, A., \& Hasanuddin, M. (2018). Perbaikan Faktor Daya Menggunakan Kapasitor Sebagai Kompensator Daya Reaktif. Seminar Nasional Royal.

[4] Grigore, V. (2001). Topological Issues In Single-Phase Power Factor Correction. Helsinki: Helsinki University Of Technology.

[5] Hajar , I., \& Rahayuni, S. M. (2020). Analisis Perbaikan Faktor Daya Menggunakan Kapasitor Bank Di Plant 6 Pt. Indocement Tunggal Prakarsa Tbk. Unit Citeurep. Jurnal IImiah Setrum.

[6] Hakim, F. M. (2014). Analisis Kebutuhan Capacitor Bank Beserta Implementasinya Untuk Memperbaiki Faktor Daya Listrik Di Politeknik Kota Malang . Jurnal Eltek.

[7] Lestari, P. D., Gunawan, \& Widihastuti, I. (2019). Analisa Perhitungan Nilai Kapasitor Bank Untuk Perbaikan Faktor Daya Pada Pt. Karya Toha Putra. Universitas Islam Sultan Agung Semarang.

[8] Lisiani, Razikin, A., \& Syaifurrahman. (2020). Identfikasi Dan Analisis Jenis Beban Listrik Rumah Tangga Terhadapa Faktor Daya (Cos Phi). Jurnal Teknik Elektro Universitas Tanjunpura.

[9] Musyahar, G. (2017). Kualitas Listrik Dan Perbaikan Faktor Daya Pada Beban Listrik Rumah Tangga Menggunakan Kapasitor. Cahaya Bagaskara Vol. 2 No-1.

[10] Nasution, I. M. (2019). Analisis Sistem Kelistrikan Pada Mesin Pipet Dan Pengaruhnya Terhadap Faktor Daya Di Cv. Fajar Baru. Medan: Universitas Muhammadiyah Sumatera Utara.

[11] Noor, F. A. (2017). Pengaruh Penambahan Kapasitor Terhadap Tegangan, Arus , Faktor Daya, Dan Daya Aktif Pada Beban Listrik Di Minimarket. Semarang: Universitar Negeri Semarang.

[12] Noor, S., \& Saputera, N. (2014). Efisiensi Pemakaian Daya Listrik Menggunakan Kapasitor Bank. Poros Teknik Vol.6 No.2.

[13] Nuraeni, R., \& Selan, C. A. (2014). Dasar Dan Pengukuran Listrik. Jakarta: Kementerian Pendidikan Dan Kebudayaan Republik Indonesia.

[14] PLN. (1985). Spln 70-1. Jakarta: PIn.

[15] PLN. (1987). Spln 72. Jakarta: Pln.

[16] PLN. (1995). Spln 1. Jakarta: PIn.

[17] Prayudi, T., \& Wiharja. (2006). Peningkatan Faktor Daya Dengan Pemasangan Bank Kapasitor Untuk Penghematan Listrik Di Industri Semen. Jurnal Teknologi Lingkungan.

[18] Rofii, A., \& Ferdinand, R. (2018). Analisa Penggunaan Kapasitor Bank Dalam Upaya Perbaikan Faktor Daya. Jurnal Kajian Teknik Elektro. 
[19] Santosa, S. E. (2020). Kajian Peningkatan Faktor Daya Menggunakan Kapasitor Bank Untuk Menghemat Biaya Listrik Pada Pelanggan Tegangan Menengah. Jakarta: Institut Teknologi PIn.

[20] Saragih, E. P. (2019). Analisa Pengaruh Pemasangan Kapasitor Bank Terhadap Beban Listrik Di Alfamart. Medan: Universitas Muhammadiyah Sumatera Barat.

[21] Suswanto, D. (2009). Sistem Distribusi Tenaga Listrik. Padang: Universitas Negeri Padang.

[22] Syawal, R. P. (2015). Analisis Pengaruh Pemasangan Kapasitor Bank Terhadap Faktor Daya (Studi Kasus Gardu Distribusi Fakultas Teknik Universitas Halu Oleo). Kendari: Universitas Halu Oleo.

[23] Syufrijal, \& Monantun, R. (2014). Jaringan Distribusi Tenaga Listrik. Jakarta: Kementerian Pendidikan Dasar Menengah Dan Kebudayaan Republik Indonesia. 